\title{
INFLUENCE OF NORMOTHERMIC SYSTEMIC PERFUSION DURING CORONARY ARTERY BYPASS OPERATIONS: A RANDOMIZED PROSPECTIVE STUDY
}

Inderpaul Birdi, FRCS

Idris Regragui, FRCS

Mohammed B. Izzat, FRCS

Alan J. Bryan, FRCS

Gianni D. Angelini, FRCS
Objectives: Normothermic cardiopulmonary bypass has been proposed as a more physiologic technique than hypothermic bypass for the maintenance of the body during cardiac surgery. The aims of this study were to investigate the effects of systemic perfusion temperature on clinical outcome after coronary revascularization. Methods: Three hundred patients (mean age $60 \pm 9$ years, $88 \%$ male) were prospectively randomized into three groups: hypothermia $\left(28^{\circ} \mathrm{C}, n=100\right)$, moderate hypothermia $\left(32^{\circ} \mathrm{C}\right.$, $n=100)$, and normothermia $\left(37^{\circ} \mathrm{C}, n=100\right)$. All patients received cold antegrade St. Thomas' Hospital crystalloid cardioplegic solution, and patients in the normothermic group were actively rewarmed during cardiopulmonary bypass (nasopharyngeal temperature $37^{\circ} \mathrm{C}$ ). Results: No differences were found between groups with respect to mortality $(1 \%)$, intraaortic balloon pump use, perioperative infarction rates, focal neurologic deficits $(\mathbf{1 \%})$, intubation time, intensive care unit stay, and postoperative hospital stay. Further stepwise regression analysis identified age and intensive care unit stay as important predictors of the variability in postoperative stay (both $\mathrm{R}^{2}=0.114 ; p<0.001$ ), whereas perfusion temperature remained a nonsignificant explanator. Normothermic perfusion necessitated larger doses of phenylephrine to maintain arterial pressure above $50 \mathrm{~mm} \mathrm{Hg}$ during cardiopulmonary bypass ( $p<0.0001$ vs $28^{\circ} \mathrm{C}, p<0.01$ vs $32^{\circ} \mathrm{C}$ ) but less requirement for electrical defibrillation during reperfusion $(p<0.05 \mathrm{vs}$ $32^{\circ} \mathrm{C}, p<0.01$ vs $28^{\circ} \mathrm{C}$ ). Total chest drainage was not different between groups, but patients undergoing normothermic cardiopulmonary bypass required less transfusion of blood $\left(p<0.05\right.$ vs $28^{\circ} \mathrm{C}$ and $32^{\circ} \mathrm{C}$ ) and platelets $\left(p<0.04\right.$ vs $32^{\circ} \mathrm{C}, p<0.001$ vs $28^{\circ} \mathrm{C}$ ) in the postoperative period. Conclusions: Cardiopulmonary bypass temperature did not influence early clinical outcome after routine coronary artery bypass operations. Normothermic systemic perfusion was associated with an increased requirement for vasoconstrictors and reduced requirements for electrical defibrillation and transfusion of blood products. (J Thorac Cardiovasc Surg 1997;114: 475-81)
From the Bristol Heart Institute, University of Bristol, Bristol, United Kingdom.

Supported by the Garfield Weston Trust and the British Heart Foundation.

Received for publication Nov. 25, 1996; revisions requested Feb. 13, 1997; revisions received March 31, 1997; accepted for publication April 1, 1997.

Address for reprints: G. D. Angelini, FRCS, British Heart Foundation Professor of Cardiac Surgery, Bristol Heart Institute, Bristol Royal Infirmary, Bristol, BS2 8HW, United Kingdom.

Copyright $\odot 1997$ by Mosby-Year Book, Inc.

$0022-5223 / 97 \$ 5.00+0 \quad \mathbf{1 2 / 1 / 8 2 3 4 9}$
Qystemic hypothermia during cardiopulmonary bypass (CPB) has been regarded as an essential component of cardiac surgery since its inception. The rationale for this has been to offer some degree of cerebral protection and to provide a safety margin in the event of technical difficulties with the CPB circuit. More recently, it has been suggested that some of the deleterious effects of CPB may be initiated or exaggerated by hypothermia. The use of normothermic techniques has been reported to confer several advantages over conventional hypothermia, such as reduced bleeding, shorter intubation times, and improved hemodynamic parameters after the operation. ${ }^{1-3}$ Current evidence is flawed, how- 
ever, by inconsistencies in cardioplegic techniques and inadequate definitions of normothermic systemic perfusion, so that the independent effects of warm blood cardioplegia and normothermic CPB remain uncertain. The aims of this prospective randomized study were to investigate the effects of hypothermic, moderately hypothermic, and actively normothermic CPB on clinical outcome after coronary artery bypass operations.

\section{Patients and methods}

Patient selection. Three hundred patients $(265$ men, mean age $60 \pm 9$ years) undergoing primary isolated coronary revascularization under the care of the academic unit were prospectively randomized by means of card allocation into one of three temperature groups $\left(28^{\circ} \mathrm{C}\right.$, $32^{\circ} \mathrm{C}$, and $37^{\circ} \mathrm{C}$ ). Prospective exclusion was limited to those with a previous history of stroke or transient ischemic episodes. The study was approved by the United Bristol Healthcare Trust, and informed consent was obtained from all patients.

Anesthetic techniques. Anesthetic techniques were standardized for all patients. Thiopental ( 1 to $3 \mathrm{mg} / \mathrm{kg}$ ) was used for induction, fentanyl ( 3 to $5 \mu \mathrm{g} / \mathrm{kg}$ ) and volatile agents delivered in a 50\% air-oxygen mixture for maintenance, and propofol ( $3 \mathrm{mg} / \mathrm{kg}$ per hour) was infused during CPB. Neuromuscular blockade was achieved by pancuronium bromide ( 0.1 to $0.15 \mathrm{mg} / \mathrm{kg}$ ), and ventilation was adjusted to maintain normocapnia. Alpha-stat acidbase management was adopted.

CPB and surgical technique. Initial heparinization was accomplished with a dose of $3 \mathrm{mg} / \mathrm{kg}$ body weight and was supplemented as needed to maintain an activated clotting time of 480 seconds. Preparation for CPB consisted of ascending aortic cannulation and two-stage venous cannulation by way of the right atrial appendage. A standard CPB circuit was used in all patients, including polyvinylchloride tubing (Sorin Biomedica UK Ltd., Midhurst, United Kingdom), a Cobe roller pump (Cobe Laboratories, Inc., Lakewood, Colo.), hollow-fiber membrane oxygenator (Monolyth, Sorin Biomedica Cardio, Saluggia, Italy), and a $40 \mu \mathrm{m}$ arterial line filter (Sorin Linea ABF 40). The extracorporeal circuit was primed with $1000 \mathrm{ml}$ Hartmann's solution, $500 \mathrm{ml}$ succinylated gelatin plasma substitute (Gelofusine, B Braun Medical Ltd., Emmenbrücke, Switzerland), $60 \mathrm{mg}$ heparin, and $0.5 \mathrm{gm} / \mathrm{kg}$ mannitol. Hypothermic and moderately hypothermic CPB were conducted with the perfusate at the appropriate temperature to reach a nasopharyngeal temperature of $28^{\circ} \mathrm{C}$ or $32^{\circ} \mathrm{C}$, respectively. Patients in the normothermic group were actively warmed to maintain a nasopharyngeal temperature of $37^{\circ} \mathrm{C}$ throughout the period of $\mathrm{CPB}$. Nonpulsatile perfusion was used throughout the procedure, and flow was maintained at a rate of $2.4 \mathrm{~L} / \mathrm{m}^{2}$ per minute for the normothermic group. This rate was reduced to 2.0 and $1.8 \mathrm{~L} / \mathrm{m}^{2}$ per minute in the moderately hypothermic and hypothermic groups, respectively, when the lowest nasopharyngeal temperatures were reached. Phenylephrine was used as necessary to maintain systemic perfusion pressures at 50 to $60 \mathrm{~mm} \mathrm{Hg}$. Myocardial protection was achieved by the induction of electromechanical arrest with cold antegrade crystalloid cardioplegia using St. Thomas' Hospital I solution and topical cooling using normal saline solution at $4^{\circ} \mathrm{C}$. One liter of cardioplegic solution was administered initially, followed by $300 \mathrm{ml}$ every 30 minutes during crossclamping or earlier whenever electrical activity was seen. Distal anastomoses were completed during a single period of aortic crossclamping. Proximal anastomoses were completed on the beating heart with the use of an aortic partial occlusion clamp. Rewarming in the hypothermic and moderately hypothermic groups was commenced at the completion of all distal anastomoses. All patients were rewarmed with a temperature difference of $8^{\circ} \mathrm{C}$ at the level of the heat exchanger between the blood and the rewarming fluid, and $\mathrm{CPB}$ was discontinued only after the patient was fully rewarmed to $37^{\circ} \mathrm{C}$. Protamine sulfate was administered to reverse the effects of heparin at a 1:1 ratio. Autologous blood predonated after anesthetic induction was used for volume replacement, and blood remaining in the circuit was reinfused to the patient via a $40 \mu \mathrm{m}$ filter (SQ40S, Pall Europe Ltd., Portsmouth, United Kingdom).

Postoperative management. At the end of the operation, patients were transferred to the cardiac intensive care unit (ICU), where they were allowed to wake up when hemodynamically stable and blood loss from the chest drains was less than $100 \mathrm{ml} / \mathrm{hr}$. When adequately rewarmed and oxygenated (an arterial oxygen tension, on an inspired oxygen fraction of $60 \%$, greater than $80 \mathrm{~mm}$ $\mathrm{Hg}$ ), patients were extubated. Postoperative homologous blood transfusion was administered if the hematocrit value fell below $25 \%$ and the patient's cardiovascular status demanded circulatory volume replacement. If the hematocrit value was higher, then synthetic colloid or plasma protein fraction was used for intravascular expansion. Excessive postoperative bleeding (greater than 200 $\mathrm{ml} / \mathrm{hr}$ ) was treated initially by the administration of protamine sulfate ( 25 to $50 \mathrm{mg}$ ) if free circulating heparin was demonstrated on a heparin-neutralizing thrombin time test. If bleeding continued and the platelet count was less than $100 \times 10^{9} / \mathrm{L}$, a therapeutic dose of platelets was transfused rapidly. Because this transfusion contains a sufficient dose of fresh plasma, the administration of fresh frozen plasma was indicated only if the activated partial thromboplastin ratio and international normalized ratio remained greater than 1.5 after platelet transfusion and if bleeding persisted. Reexploration for bleeding was undertaken if blood loss continued at a rate of more than 200 $\mathrm{ml} / \mathrm{hr}$ for 3 hours despite the aforementioned therapeutic measures or if blood loss was rapid and could not be replaced without compromising the hemodynamic state of the patient. Chest drains were removed when blood loss fell below $30 \mathrm{ml} / \mathrm{hr}$ for 2 consecutive hours. Drainage was recorded as total and 12-hour loss. The degree of inotropic support was defined as minimal (dopamine above 3 $\mu \mathrm{g} / \mathrm{kg}$ per minute or dobutamine up to a dose of $5 \mu \mathrm{g} / \mathrm{kg}$ per minute), moderate (dopamine $\geq 5 \mu \mathrm{g} / \mathrm{kg}$ per minute or dobutamine at 5 to $15 \mu \mathrm{g} / \mathrm{kg}$ per minute), and maximum (the use of epinephrine, the combination of three or more different inotropic agents, and/or the use of an intraaortic balloon pump). The selective use of thermodilution catheters to evaluate hemodynamic parameters was 
undertaken at the discretion of the clinicians involved in the management of the patient. Perioperative infarction was diagnosed by examination of serial 12-lead electrocardiograms recorded before the operation and up to 5 days after the operation. Evidence of infarction was diagnosed by the presence of new $\mathrm{Q}$ waves of $0.04 \mathrm{~mm}$ or more or by a reduction in the $\mathrm{R}$ wave of $25 \%$ or more in two or more leads.

Statistical analysis. Data are presented as mean \pm standard deviation unless stated otherwise. Unpaired comparisons of continuous variables were undertaken with the use of the Mann-Whitney $U$ test and nominal variables were compared with the use of $\chi^{2}$ analysis. Stepwise multiple regression analyses were performed on the length of postoperative hospital stay to maximize the chance of detecting any influence of CPB temperature by allowing for the effects of confounding variables. Variables offered included age, sex, urgency of the operation (need for surgery within the same hospital admission), number of grafts performed, CPB time, aortic crossclamp time, surgeon grade (consultant or trainee), intubation time, ICU stay, and position on operating room list. Temperature was offered as binary dummy variables, one to indicate any difference between the hypothermic and moderately hypothermic groups and the other to indicate any difference between the moderately hypothermic and normothermic groups.

\section{Results}

Demographic data. Groups were matched with regard to major preoperative demographic and operative variables (Table I). Preoperative angiographic data demonstrated left ventricular ejection fraction less than 0.5 in $22 \%$ of patients. Eleven percent of patients were older than 70 years of age. The majority of patients had mild to moderate angina and were at relatively low risk according to the Parsonnet classification. ${ }^{4}$

Operative data. No significant differences were observed between groups with regard to number of grafts, doses of cardioplegic solution, and CPB and aortic crossclamp times (Table II). A single internal thoracic artery was used in $89 \%$ of patients and more than one arterial conduit was used in $10 \%$. The doses of vasoconstrictor required to maintain a perfusion pressure above $50 \mathrm{~mm} \mathrm{Hg}$ during CPB were significantly higher during normothermic systemic perfusion $\left(p<0.01\right.$ vs $28^{\circ} \mathrm{C}$ and $32^{\circ} \mathrm{C}$ ). Despite this, the systemic vascular resistance remained significantly lower $\left(p<0.001\right.$ vs $28^{\circ} \mathrm{C}$ ). Electrical defibrillation to restore sinus rhythm after reperfusion was required less frequently after normothermic than after hypothermic CPB $(p<0.001$ vs $28^{\circ} \mathrm{C}, p<0.01$ vs $32^{\circ} \mathrm{C}$ ).

Mortality and morbidity. Three patients died in the study $\left(28^{\circ} \mathrm{C}, n=2 ; 37^{\circ} \mathrm{C}, n=1\right)$. The incidence
Table I. Demographic variables

\begin{tabular}{lccc}
\hline & \multicolumn{3}{c}{$C P B$ temperature } \\
\cline { 2 - 4 } & $28^{\circ} \mathrm{C}$ & $32^{\circ} \mathrm{C}$ & $37^{\circ} \mathrm{C}$ \\
\hline Age (yr) & $59.8 \pm 8.8$ & $60.2 \pm 8.9$ & $60.4 \pm 8.7$ \\
Sex (M/F) & $88 / 12$ & $85 / 15$ & $92 / 8$ \\
BSA (m $\left.{ }^{2}\right)$ & $1.9 \pm 0.2$ & $1.9 \pm 0.1$ & $2.0 \pm 0.5$ \\
Angina class & & & \\
I & 6 & 11 & 10 \\
II & 48 & 40 & 59 \\
III & 38 & 38 & 21 \\
IV & 8 & 11 & 10 \\
Hypertension & 22 & 24 & 21 \\
Diabetes mellitus & 5 & 7 & 4 \\
Peripheral vascular disease & 3 & 3 & 5 \\
Parsonnet score & & & \\
$\quad 0-5$ & 81 & 80 & 85 \\
5-10 & 17 & 17 & 13 \\
$\quad 10$ & 2 & 3 & 2 \\
Elective operation & 85 & 83 & 93 \\
Urgent operation & 15 & 17 & 7 \\
\hline
\end{tabular}

$B S A$, Body surface area.

of perioperative infarction (6.7\%) and intraaortic balloon pump use $(4.3 \%)$ were not significantly different between groups (see Table II). Two patients had a stroke, and neurologic signs were apparent on the first postoperative day $\left(32^{\circ} \mathrm{C}\right.$ and $37^{\circ} \mathrm{C}$ ). Both patients made a good recovery, with lessening of their neurologic disability at 6 weeks' follow-up.

Use of inotropic drugs. Inotropic drugs were used more frequently after normothermic perfusion than after hypothermic perfusion $\left(p<0.05\right.$ vs $28^{\circ} \mathrm{C}$ and $32^{\circ} \mathrm{C}$; Fig. 1). However, the majority of patients received only minimal doses to maintain mean arterial pressure above $65 \mathrm{~mm} \mathrm{Hg}$, and $90 \%$ of them were given dopamine as the inotropic agent of choice at doses ranging between 3 and $5 \mu \mathrm{g} / \mathrm{kg}$ per minute.

Blood loss and blood product use. Five patients required reexploration for excessive bleeding on the day of the operation, but this complication was not associated with perfusion temperature. For all patients in the study, total chest tube drainage, loss per unit body surface area per unit time, and 12-hour blood loss were also not significantly different between groups (see Table II). However blood and blood product transfusion were used less frequently after normothermic $\mathrm{CPB}$, and the association with perfusion temperature was clear (Fig. 2). A similar trend was seen when comparing the mean number of units of blood and blood products that were transfused (Fig. 3). 
Table II. Operative and postoperative variables

\begin{tabular}{lccc}
\hline & & $C P B$ temperature & $37^{\circ} C$ \\
\cline { 2 - 4 } & $28^{\circ} C$ & $32^{\circ} C$ & $3.0 \pm 0.9$ \\
\hline Number of grafts & $3.2 \pm 0.8$ & $3.0 \pm 0.9$ & 90 \\
ITA & 94 & 85 & $82 \pm 24$ \\
CPB time (min) & $83 \pm 21$ & $80 \pm 26$ & $38 \pm 13$ \\
Aortic crossclamp time (min) & $39 \pm 13$ & $36 \pm 14$ & $768 \pm 142^{*}$ \\
SVR (dyne $\cdot$ sec $\cdot \mathrm{cm}^{-5}$ ) & $923 \pm 197$ & $814 \pm 156$ & $5.2 \pm 4.8^{\dagger}$ \\
Phenylephrine (mg) & $3.7 \pm 3.6$ & $3.1 \pm 2.6$ & $20 \%$ \\
Electrical defibrillation & 77 & 36 & 6 \\
Perioperative infarction & 6 & 8 & 4 \\
Intraaortic balloon pump use & 3 & 6 & 1 \\
Deaths & 2 & 0 & 1 \\
Stroke & 0 & 1 & $9.0 \pm 6.9$ \\
Period of intubation (hr) & $8.6 \pm 5.8$ & $23 \pm 7.7$ & $22 \pm 10$ \\
ICU stay (hr) & $22 \pm 9$ & $7.7 \pm 2.0$ & $7.7 \pm 2.3$ \\
Postoperative stay (days) & $7.0 \pm 1.3$ & $1.2 \pm 0.6$ & $1.1 \pm 0.4$ \\
Total blood loss (L) & $1.2 \pm 0.5$ & $26.2 \pm 13.4$ & $22.6 \pm 10$ \\
Corrected loss (L/m $\left.{ }^{2} / \mathrm{hr}\right)$ & $23.4 \pm 8.6$ & $0.6 \pm 0.3$ & $0.5 \pm 0.2$ \\
Twelve-hour blood loss (L) & $0.6 \pm 0.2$ & $1 / 1$ & $2 / 1$ \\
Reoperation (bleeding/LCOS) & $2 / 1$ & & \\
\hline
\end{tabular}

$I T A$, Internal thoracic artery; $S V R$, systemic vascular resistance; $L C O S$, low cardiac output state.

${ }^{*} p<0.001$ versus $28^{\circ} \mathrm{C}$.

$\dagger p<0.001$ versus $28^{\circ} \mathrm{C}$ and $32^{\circ} \mathrm{C}$.

$\ddagger p<0.001$ versus $28^{\circ} \mathrm{C}, p<0.01$ versus $32^{\circ} \mathrm{C}$.

Intensive care and postoperative hospital stay. Systemic perfusion temperature did not influence the period of postoperative intubation or the total length of ICU and postoperative inpatient stay (see Table II). Stepwise regression identified age and ICU stay as significant explanators of postoperative hospital stay (both $\mathrm{R}^{2}=0.114 ; p<0.0001$ ). However, systemic perfusion temperature remained a nonsignificant explanator. The relationship between postoperative hospital stay, age, and ICU stay can be expressed mathematically as follows:

Postoperative stay (days) $=3.794+0.04$

$$
\text { (Age [years]) }+0.04 \text { (ICU stay [hours]) }
$$

\section{Discussion}

The results of this randomized investigation suggest that the systemic perfusion temperatures studied did not influence mortality, perioperative myocardial infarction, stroke, and intraaortic balloon pump use after coronary artery operations. One explanation for these results may be that the patients studied were at relatively low risk, so that effects of any changes in systemic perfusion temperature were of less importance. In addition, it is possible that the multifactorial influences of clinical outcome after coronary artery operations outweighed any small effect of systemic perfusion tem- perature on mortality and morbidity; because the frequency of such events was low, a much larger study would have been required to demonstrate differences in these end points. The study size was therefore calculated on the chance of detecting a $14 \%$ change in our current estimate of postoperative hospital stay. Postoperative hospital stay in our institution was estimated to be $7.3 \pm 1.6$ days (mean \pm standard deviation). Assuming that a clinically meaningful reduction would be 1 day (14\%), a sample size of 100 patients in each group would have been required to allow a $90 \%$ chance of detecting an effect of perfusion temperature with $95 \%$ confidence. The duration of postoperative stay did not differ between groups, but to avoid dismissing the possibility of a significant effect of perfusion temperature, we undertook a stepwise regression analysis. This identified age and ICU stay as significant explanators of the variability in hospital stay. Despite allowance for these and other confounding variables, CPB temperature remained a nonsignificant explanator. This observation lends support to the observed similarities in morbidity and mortality data among the three groups; any important differences in these end points would have been expected to have influenced postoperative stay.

Some important differences in the management of patients undergoing normothermic systemic perfu- 


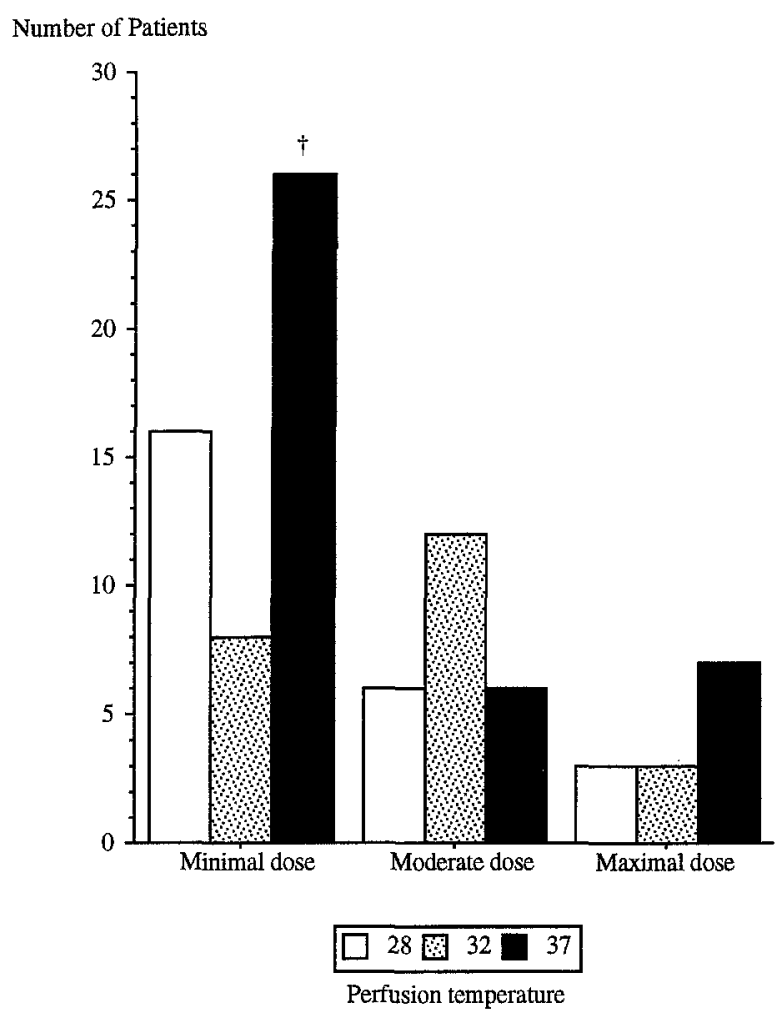

Fig. 1. Distribution of degree of inotropic support required after the operation. $\uparrow$ Ninety percent of patients received dopamine at a dose between 3 and $5 \mu \mathrm{g} / \mathrm{kg}$ per minute.

sion need to be appreciated and deserve some discussion. In agreement with the findings of other workers, the systemic vascular resistance was lower during normothermic $\mathrm{CPB}$, and significantly larger doses of vasoconstrictors were administered in the warm group to maintain adequate perfusion pressures..$^{5-7}$ This may represent a limitation of normothermia: First, the maintenance of CPB perfusion pressure requires increased vigilance on the part of the perfusionists to avoid hypoperfusion of the major organs, particularly with respect to the warm, metabolically active brain; second, increased vasoconstrictor administration may be detrimental to blood flow along arterial conduits. DiNardo and associates $^{8}$ demonstrated a significant decrease in internal thoracic artery graft flow when phenylephrine $(76 \pm 31 \mu \mathrm{g} / \mathrm{min})$ was used to elevate mean arterial pressures by $20 \mathrm{~mm} \mathrm{Hg}$. Using a canine model in which blood pressure, heart rate, and cardiac output remained constant, Jett and cowork$\mathrm{ers}^{9}$ significantly reduced internal thoracic artery
Number of patients

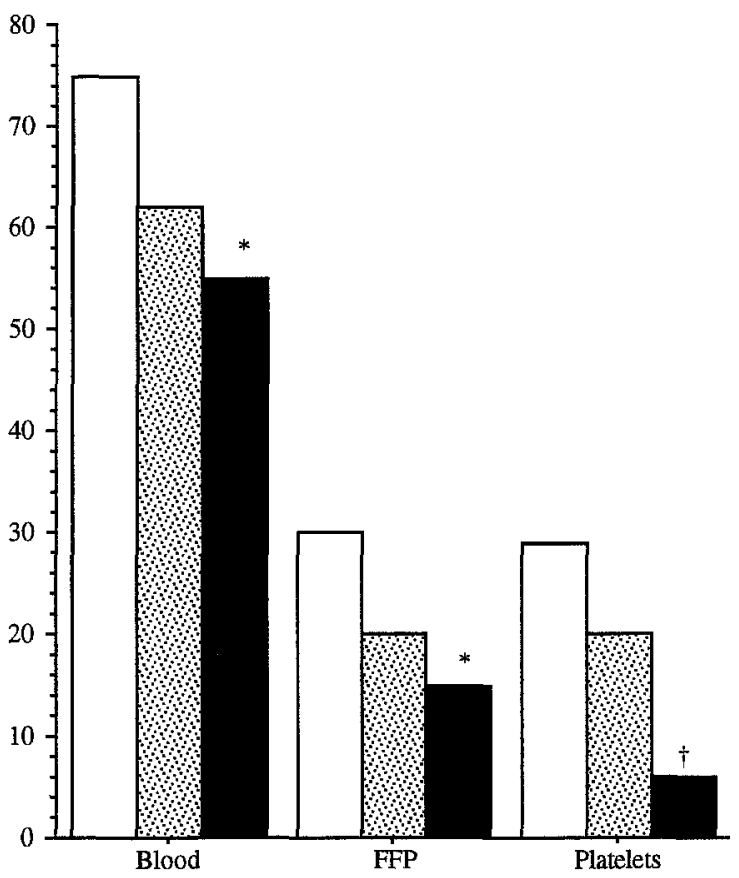

$\square 28 \square 32 \square 37$

Perfusion temperature

Fig. 2. Number of patients requiring transfusion of blood and blood products. ${ }^{*} p<0.05$ versus $28^{\circ} \mathrm{C} ; t p<0.05$ versus $28^{\circ} \mathrm{C}$ and $32^{\circ} \mathrm{C}$.

flow after administration of phenylephrine at a dose of $2 \mu \mathrm{g} / \mathrm{min}$.

The observation that patients in the normothermic group required minimal doses of inotropic agents in the early postoperative period was not reflected by differences in intraaortic balloon pump support and perioperative myocardial infarction rates in the study. Although this is only a clinical observation, patients in the normothermic group were often observed to remain warm and well perfused peripherally, and the pattern of inotropic use in the intensive care may have reflected the continued vasodilation associated with warm CPB.

The heart reverted to sinus rhythm after removal of the crossclamp more often after normothermic CPB than after hypothermic $\mathrm{CPB}$, an observation that has been previously demonstrated by others using warm blood cardioplegia. ${ }^{5}$ Whether this results in a reduction in reperfusion injury is not known but would be a useful area for further study.

Only five patients returned to the operating room 


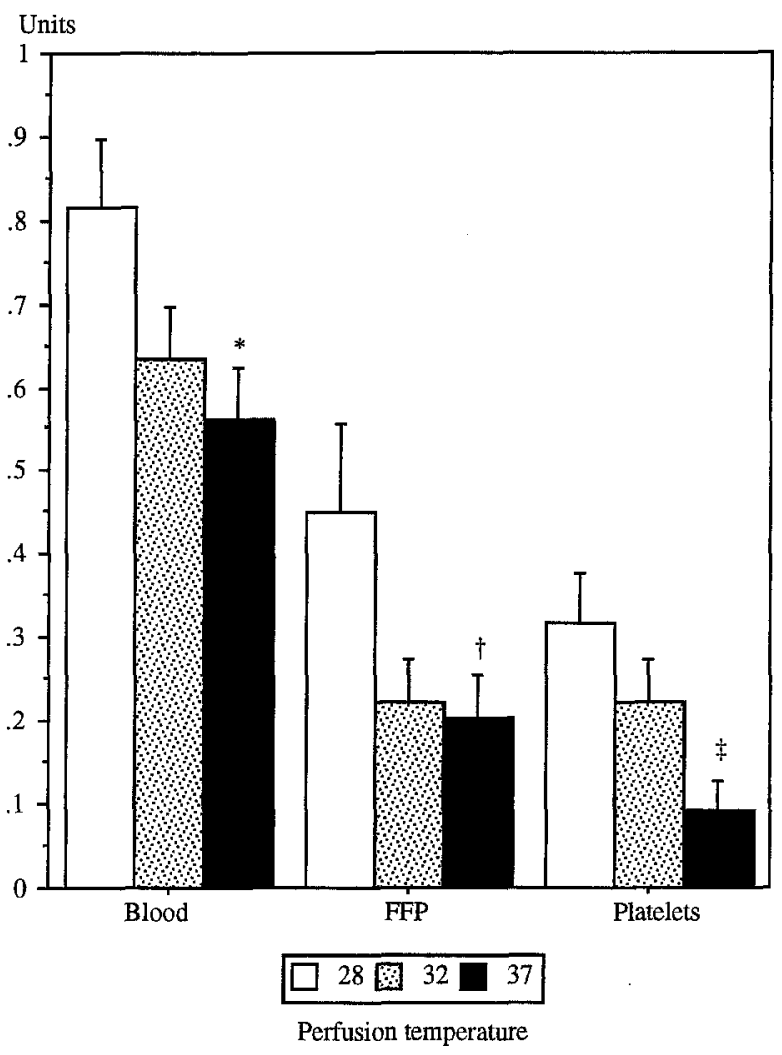

Fig. 3. Units of blood and blood products transfused. ${ }^{*} p<0.02$ versus $28^{\circ} \mathrm{C} ; \dagger p<0.05$ versus $28^{\circ} \mathrm{C} ; t p<0.002$ versus $28^{\circ} \mathrm{C}, p<0.04$ versus $32^{\circ} \mathrm{C}$.

because of continued bleeding after the operation, so that any statistical comparison between groups was not possible. Total chest tube drainage in the present study was not different between the groups, which contradicts the findings of others who have suggested a reduced bleeding tendency after normothermic perfusion. ${ }^{10-12}$ However, the increased use of blood transfusion when the hematocrit value fell below $25 \%$ and the reduced need for fresh frozen plasma and platelet transfusion in the normothermic group did lend support to the concept of reduced postoperative coagulopathy state after warm systemic perfusion.

Although normothermic systemic perfusion was at least as safe as conventional hypothermic CPB for routine coronary revascularization in this study, it nevertheless offered no major advantage with regard to clinical outcome. In addition, we have previously found no beneficial influence of normothermic systemic perfusion temperature on pulmonary gas exchange ${ }^{13}$ and renal function. ${ }^{14}$ The reduced incidence of ventricular fibrillation on reperfusion and the lower requirements for transfusion of potentially harmful blood products, although favorable, need to be appreciated within the context of the growing evidence from randomized investigations that associates normothermia with an increased incidence of cerebral dysfunction. Martin and colleagues ${ }^{15}$ conducted a randomized trial of warm blood cardioplegia and systemic normothermia $\left(\geq 35^{\circ} \mathrm{C}\right)$ versus cold crystalloid cardioplegia and hypothermic perfusion $\left(\leq 28^{\circ} \mathrm{C}\right)$ and demonstrated significantly higher stroke rates in the normothermic group ( $3.1 \%$ vs $1.0 \%$, respectively). The authors subsequently reported a multivariate analysis to address the criticisms of their initial findings that blood glucose was elevated in the normothermic group. This analysis did not identify systemic blood glucose as a predictor for stroke in the series. ${ }^{15-17}$ In another study, Craver and associates ${ }^{17}$ investigated 379 patients undergoing coronary artery operations with hypothermic retrograde blood cardioplegia and hypothermic perfusion $\left(29^{\circ} \mathrm{C}\right.$ to $\left.33^{\circ} \mathrm{C}\right)$ and compared them with retrospective control subjects receiving retrograde warm blood cardioplegia and normothermic perfusion. The incidence of postoperative neurologic events, however, was significantly higher in the normothermic group ( $4.7 \%$ vs $1.8 \%$ ), substantiating concerns regarding the deleterious effects of normothermic perfusion on cerebral integrity. Mora and coworkers ${ }^{18}$ have also found perioperative neurologic injury to be more prevalent after normothermic $\left(>35^{\circ} \mathrm{C}\right) \mathrm{CPB}$. We recently completed a prospective randomized study in which 96 patients were randomized into one of three groups according to $\mathrm{CPB}$ temperature $\left(28^{\circ} \mathrm{C}, 32^{\circ} \mathrm{C}\right.$, and $\left.37^{\circ} \mathrm{C}\right)$ and cold antegrade crystalloid cardioplegia was used in all cases. Patients were subjected to detailed neurologic examination after the operation, and neuropsychologic evaluation was undertaken both before and 6 weeks after the operation using the Wechsler Adult Intelligence Scale-revised. Although no focal neurologic deficits were recorded in the study, detailed multivariate analyses suggested that the incidence of neuropsychologic deficit was higher after normothermic perfusion $\left(37^{\circ} \mathrm{C}\right)$ than after moderate hypothermic perfusion $\left(32^{\circ} \mathrm{C}\right)$, with no added benefit conferred by lowering perfusion temperature to $28^{\circ} \mathrm{C}^{19}$ Some evidence suggests that normothermia does not result in an increased risk of stroke, ${ }^{3,20}$ and the controversy remains to be resolved, but if normothermic CPB proves to be detrimental to cerebral function, there may be little incentive for its routine use during coronary artery operations. 


\section{Conclusions}

$\mathrm{CPB}$ temperature did not influence early clinical outcome after routine coronary artery bypass operations. Normothermic systemic perfusion was associated with an increased requirement for vasoconstrictors and reduced requirements for electrical defibrillation and transfusion of blood products.

\section{REFERENCES}

1. Singh AK, Feng WC, Bert AA, Rotenberg FA, Sanofsky SJ. Warm body, cold heart surgery: clinical experience in 2817 patients. Eur J Cardiothorac Surg 1993; 7:225-30.

2. Tonz M, Mihaljevic T, Pasic M, von Segesser LK, Turina M. The warm versus cold perfusion controversy: a clinical comparative study. Eur J Cardiothorac Surg 1993;7:623-7.

3. The Warm Heart Investigators. Randomised trial of normothermic versus hypothermic coronary bypass surgery. Lancet 1994;343:559-63.

4. Parsonnet V, Dean D, Bernstein AD. A method of uniform stratification of risk for evaluating the results of surgery in acquired adult heart disease. Circulation 1989;79(Suppl):I312.

5. Christakis G, Koch JP, Deemar KA, et al. A randomized study of the systemic effects of warm heart surgery. Ann Thorac Surg 1992;54:449-59.

6. Lehot JJ, Villard J, Piriz H, et al. Hemodynamic and hormonal responses to hypothermic and normothermic cardiopulmonary bypass. J Cardiovasc Anesth 1992;6:132-9.

7. Arom KV, Emery RW, Northrup WF III. Warm heart surgery: a prospective comparison between normothermic and tepid temperature. J Card Surg 1995;10:221-6.

8. DiNardo JA, Bert A, Schwartz MJ, et al. Effects of vasoactive drugs on flows through left internal mammary artery and saphenous vein grafts in man. J Thorac Cardiovasc Surg 1991;102:730-5.

9. Jett GK, Arcidi JM, Dorsey LMA, et al. Vasoactive drug effect on blood flow in internal mammary artery and saphenous vein grafts. J Thorac Cardiovasc Surg 1987;94:2-11.
10. Boldt J, Knothe C, Zickmann B, et al. Platelet function in cardiac surgery: influence of temperature and aprotinin. Ann Thorac Surg 1993;55:652-8.

11. Boldt J, Knothe C, Welters I, et al. Normothermic versus hypothermic cardiopulmonary bypass: Do changes in coagulation differ? Ann Thorac Surg 1996;62:130-5.

12. Tonz M, Mihaljevic T, von Segesser L, et al. Normothermia versus hypothermia during cardiopulmonary bypass: a randomized controlled trial. Ann Thorac Surg 1995;59:127-43.

13. Birdi I, Regragui I, Izzat MB, et al. The effects of cardiopulmonary bypass temperature on pulmonary gas exchange after coronary artery surgery. Ann Thorac Surg 1996;61:118-23.

14. Regragui I, Izzat MB, Birdi I, et al. Cardiopulmonary bypass perfusion temperature does not influence perioperative renal function. Ann Thorac Surg 1995;60:160-4.

15. Martin T, Craver J, Gott J, et al. A prospective randomized trial of retrograde warm blood cardioplegia: myocardial benefit and neurological threat. Ann Thorac Surg 1994;57: 298-304.

16. Mellitt RJ, Weintraub WS, Craver JM, et al. The interrelationship of age and normothermic blood vs cold crystalloid cardioplegia on the incidence of stroke in elective coronary artery bypass grafting: results of the Emory Randomized trial. Circulation 1993;88(Suppl):I288.

17. Craver JM, Bufkin BL, Weintraub WS, et al. Neurologic events after coronary bypass grafting: further observations with warm cardioplegia. Ann Thorac Surg 1995;59:1429-34.

18. Mora CT, Henson MB, Weintraub WS, et al. The effect of temperature management during cardiopulmonary bypass on neurologic and neuropsychologic outcomes in patients undergoing coronary revascularization. $\mathbf{J}$ Thorac Cardiovasc Surg 1996;112:514-22.

19. Regragui I, Birdi I, Izzat MB, et al. The effects of cardiopulmonary bypass temperature on neuropsychologic outcome after coronary artery surgery: a prospective randomized trial. J Thorac Cardiovasc Surg 1996;112:1036-45.

20. Singh A, Bert A, Feng W, Rotenberg F. Stroke during coronary artery bypass grafting using hypothermic versus normothermic perfusion. Ann Thorac Surg 1994;59;84-9. 